\title{
Transplant Livers in Wilson's Disease for Hepatic, not Neurologic, Indications
}

\section{To the Editors:}

We are very concerned by the report entitled, "Liver Transplantation for Wilson's Disease: A Single-Center Experience" which appeared in your journal (vol 5, pp 467-474, November 1999). ${ }^{1}$ Throughout the article, the authors infer, and in some places outright claim, that orthoptic liver transplantation (OLT) is an effective, and perhaps advantageous, way to treat the neurological symptoms of Wilson's disease. For example, the last sentence of the abstract: "Earlier transplantation in patients with an unsatisfactory response to medical treatment may prevent irreversible neurological deterioration and less satisfactory improvement after OLT."

This statement leads to a risk that OLT will be used to manage neurological symptoms; in our opinion, this would be a serious mistake. The authors are apparently unaware that OLT is simply another anticopper therapy as far as neurological symptoms, other than hepatic encephalopathy, are concerned. The risks of morbidity and mortality from needless transplantation resulting from such assertions are of concern.

The neurological symptoms of Wilson's disease are caused by copper toxicity in specific areas of the brain, areas that coordinate movement. ${ }^{2,3}$ Any approach to reducing copper levels below toxic levels will stop further copper damage at that point, but symptoms arising from that damage will not begin improving until 5 to 6 months later, and will continue to improve for another 18 months (24 months from initiation of anticopper therapy). 2,4,5 In other words, anticopper drugs and OLT have no direct effect on the neurological symptoms, they only control copper. The brain has to repair itself, and will, slowly, to the extent that damage isn't irreversible.

The authors speak of "an unsatisfactory response to medical treatment" and suggest that "earlier transplantation" "may prevent irreversible neurological deterioration." If "an unsatisfactory response to medical treatment" means the failure to respond in the first 6 months, this is simply the natural history of the repair of the injury. None of the brain damage from copper toxicity will have repaired itself enough to allow symptomatic improvement during the first 5 to 6 months of anticopper therapy..$^{5-7}$ It is not valid to claim an unsat- isfactory response to medical therapy during this period. Yet, if they are transplanted during this period, they will likely then improve (being in the 6- to 18 month window when neurological improvement occurs), appearing to justify the authors' concept that OLT has done something beyond what anticopper drugs are able to do. If "an unsatisfactory response to medical treatment" means the persistence of symptoms, sometimes quite disabling, after 2 years of therapy, these symptoms are permanent and will not be helped by any anticopper therapy, including OLT.2,4-7 The authors seemed to have bumped into this phenomenon in some of their patients, but attribute the problem to patients not receiving transplants early enough, rather than to some patients simply having relatively severe and permanent damage.

There is one caveat to this discussion, and that is, we are not talking about using penicillamine for initial treatment of neurologically presenting Wilson's disease patients. Penicillamine should never be used in this setting because it causes $50 \%$ of patients to get worse neurologically, and $25 \%$ never recover. ${ }^{8}$

The great risk from the authors' report is that some physicians, following their advice, are going to have patients undergo transplants for the wrong indications and, therefore, needlessly. For the last 20 years, one of us (G.J.B.) has struggled to improve the therapy of Wilson's disease and has seen and treated 250 patients, 100 of whom were referred for initial neurological treatment. Based on that experience, we offer the following guidelines:

1. Never transplant in Wilson's disease because of the neurological symptoms related to copper toxicity. Anything OLT can do for neurological symptoms, anticopper drugs can also do without the up-to-30\% long-term mortality and extensive morbidity.

2. Transplant only in Wilson's disease based on a liver disease status in which transplantation, versus medical therapy, represents the most favorable option for the patient. Obviously, fulminant hepatic failure falls into this category. But even in patients with cirrhosis with mild hepatic decompensation, such as ascites, mild hyperbilirubinemia, and portal hypertension, we are often able to treat the patient medically, the liver disease is partially reversible, and the 
patients do well. Borderline cases of more pronounced hepatic decompensation can be difficult. If they go sour, hepatic transplantation sometimes has to be performed under less than ideal circumstances, if a liver is available. We use the prognostic index of Nazer et al ${ }^{9}$ to help triage these patients.

3. Don't forget that patients with the liver disease of Wilson's generally may have a more favorable prognosis with medical therapy than alcoholic and viral hepatitis patients, in that there is specific and uniformly effective treatment, and a substantial hepatic recovery after anticopper therapy (generally between 4 and 12 months after therapy initiation).

4. Save livers for people who really need them. Because donor livers are in such short supply and the demand for transplantation is growing at an alarming rate, the decision to perform transplantation on a patient for neurologic indications who would fare as well or better with medical therapy as surgical therapy not only does that individual a disservice, but actually means that someone else who could have been helped may die needlessly.

5. As with any condition, the optimal treatment of Wilson's disease requires specific experience and expertise, which, because of the rarity of the disease, will not be available at every medical center. Some guidance can be obtained through the Wilson's Disease Association web site, www.wilsonsdisease.org.

\section{Acknowledgment}

Our work on Wilson's disease was supported in part by Food and Drug Administration grants FD-R-000179 and FD-U000505. The work with zinc therapy was also assisted by Gate Pharmaceutical Co, Montgomeryville, PA. We also acknowledge the assistance and support of the Clinical Research Center of the University of Michigan Hospitals, supported in part by National Institutes of Health grant M01-RR00042.

\section{References}

1. Eghtesad B, Nezakatgoo N, Geraci LC, Jabbor N, Irish WD, Marsh W, Fung JT, Rakela J. Liver transplantation for Wilson's disease: A single center experience. Liver Transpl Surg 1999;5: 467-474.

2. Brewer GJ, Yuzbasiyan-Gurkan V. Wilson disease. Medicine 1992;71:139-164.

3. Scheinberg IH, Sternlieb I. Wilson's disease. In: Smith LH Jr, ed. Major Problems in Internal Medicine, vol 23. Philadelphia, PA: Saunders, 1984.

4. Brewer GJ, Dick RD, Johnson V, Brunberg JA, Kluin KJ, Fink JK. Treatment of Wilson's disease with zinc: XV. Long-term follow-up studies. J Lab Clin Med 1998;132:264-278.
5. Brewer GJ, Johnson V, Dick RD, Wang Y, Kluin KJ, Fink JK, Brunberg JA. Treatment of Wilson disease with ammonium tetrathiomolybdate: II. Initial therapy in 33 neurologically affected patients and follow-up with zinc therapy. Arch Neurol 1996;53: 1017-1025.

6. Brewer GJ, Dick RD, Johnson V, Wang Y, Yuzbasiyan-Gurkin V, Kluin KJ, Fink JK, Aisen A. Treatment of Wilson's disease with ammonium tetrathiomolybdate: I. Initial therapy in 17 neurologically affected patients. Arch Neurol 1994;51:545-554.

7. Brewer GJ, Dick RD, Yuzbasiyan-Gurkin V, Tanakow R, Young $\mathrm{AB}$, Kluin KJ. Initial therapy of patients with Wilson's disease with tetrathiomolybdate. Arch Neurol 1991;48:42-47.

8. Brewer GJ, Terry CA, Aisen AM, Hill GM. Worsening of neurologic syndrome in patients with Wilson's disease with initial penicillamine therapy. Arch Neurol 1987;44:490-493.

9. Nazer H, Ede RJ, Mowat AP, Williams R. Wilson's disease: Clinical presentation and use of prognostic index. Gut 1986;27:13771381.

George J. Brewer

Departments of Human Genetics and Internal Medicine University of Michigan Medical School Ann Arbor, MI

Frederick Askari Division of Gastroenterology Department of Internal Medicine University of Michigan Medical School Ann Arbor, MI

doi: 10.1053 /jlts.2000.18136

\section{Response}

After reading the long and acrimonious letter of Drs Brewer and Askari, we are not clear as to its purpose apart from indulging in self-citation. The authors did not seem to realize that the indication for liver transplantation in all of our 45 patients was fulminant, subacute, or chronic hepatic failure. We had no instance of Wilson's disease presenting solely with neurological symptoms as an indication for liver transplantation in our 45 patients. Furthermore, we said in our publication that the use of liver transplantation is controversial for patients presenting only with neurological symptoms. Fourteen of our patients, apart from their hepatic manifestations, also had Wilsonian neurological manifestations. Ten of these patients showed significant neurological improvement after liver transplantation.

The authors also seem to be unaware of several publications ${ }^{1-4}$ in which liver transplantation has been used 
for patients presenting only with severe neurological manifestations due to Wilson's disease and failed medical treatment, with significant recovery.

Lastly, we consider it irresponsible to conclude from our report that liver transplantation should be offered as a first line of treatment to patients with hepatic or neurological Wilson's disease, with the exception of patients with Wilson fulminant hepatic failure.

\section{References}

1. Polson RJ, Rolles K, Calne RY, Williams R, Marsden D. Reversal of severe neurological manifestations of Wilson's disease following orthotopic liver transplantation. Q J Med 1987;64:685-691.

2. Chen CL, Chen YS, Lui CC, Hsu SP. Neurological improvement of Wilson's disease after liver transplantation. Transplant Proc 1997;29:497-498.

3. Schumacher G, Platz KP, Mueller AR, Neuhaus R, Steinmuller T, Bechstein WO, et al. Liver transplantation: Treatment of choice for hepatic and neurological manifestation of Wilson's disease. Clin Transplant 1997;11:217-224.

4. Bax RT, Hassler A, Luck W, Hefter H, Krageloh-Mann I, Neuhaus P, Emmrick P. Cerebral manifestation of Wilson's disease successfully treated with liver transplantation. Neurology 1998; 51:863-865.

Bijan Eghtesad

Department of Surgery, 2-ACC

Division of Transplantation

University of New Mexico

Albuquerque, NM

John J. Fung

Division of Transplantation Surgery University of Pittsburgh Medical Center

Pittsburgh, PA

Jorge Rakela

Transplantation Division Mayo Clinic Hospital

Phoenix, AZ

doi: 10.1053/jlts.2000.18138 